\title{
Anesthetic considerations in patients with large obstructing vocal process granuloma
}

\author{
Ji Seon Jeong ${ }^{1}$, Kyo Sang Kim ${ }^{1}$ Mi Ae Jeong ${ }^{1}$, Jae Hyun Cho ${ }^{1}$, and Kyung Tae ${ }^{2}$ \\ Departments of ${ }^{1}$ Anesthesiology and Pain Medicine, ${ }^{2}$ Otolaryngology-Head and Neck Surgery, College of Medicine, Hanyang \\ University, Seoul, Korea
}

Dangerous problems can arise during the induction of general anesthesia in patients with huge vocal process granuloma, due to airway obstruction [1]. A 54 year-old female patient was referred to our institution from a local clinic due to persistent hoarseness and severe dyspnea, over the last 3 months after subtotal gastrectomy with a diagnosis of a postintubation granuloma. She was scheduled for a laryngomicroscopic surgery under general anesthesia. We decided to use direct larygoscope for endotracheal intubation with patient's cooperation. She was kept awake with conscious sedation during intubation with remifentanil $0.1 \mu \mathrm{g} / \mathrm{kg} / \mathrm{min}$ IV. The topical anesthesia with two to three sprays of aerosolized $10 \%$ xylocaine was performed onto the backside of the tongue, the soft palate, the pharynx and the larynx in the oral cavity. This was followed by an injection of $2 \mathrm{ml}$ of $2 \%$ lidocaine to block the lingual branch of the superior laryngeal nerves. Direct laryngoscope was applied. We confirmed there was space on the left side on the vocal cord during patient's deep expiration, and the granuloma was not fixed. An assistant put aside the granuloma in the space to the right by the suction tip. An anesthesiologist inserted an endotracheal tube with an inner diameter of 5.0 $\mathrm{mm}$ into which a stylet was inserted during patient's deep expiration. The tube was carefully inserted not to cut off the mass into the trachea (Fig. 1). No fragments of damaged tissue were found. After successful intubation, propofol $120 \mathrm{mg}$ and rocuronium $30 \mathrm{mg}$ were injected intravenously, and anesthesia was maintained with sevoflurane 2 vol\% and remifentanil $0.1-$ $0.2 \mu \mathrm{g} / \mathrm{kg} / \mathrm{min}$. Dexamethasone $10 \mathrm{mg}$ was administered to prevent postoperative laryngeal edema. Surgeon performed a laryngomicroscopic excision for granuloma mass, which continued for $15 \mathrm{~min}$.

Prolonged endotracheal intubation of greater than four hours may result in the development of vocal process granulomas in $0.01 \%$ to $3.5 \%$ of patients [2]. When there is no surgical indication for a tracheostomy, two options exist: direct laryngoscopy or flexible fiberscope guided endotracheal

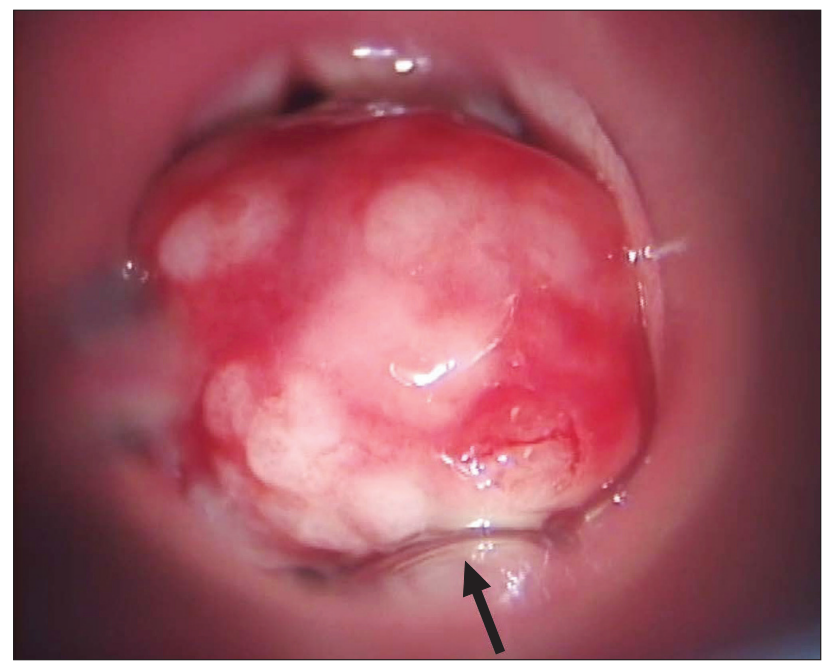

Fig. 1. Laryngo-microscopic view of a huge vocal process granuloma after intubation. The glottis is almost completely obstructed due to a huge vocal process granuloma. The black arrow shows the endotracheal tube.

Corresponding author: Kyo Sang Kim, M.D., Ph.D., Department of Anesthesiology and Pain Medicine, Hanyang University Hospital, 17, Haengdang-dong, Sungdong-gu, Seoul 133-792, Korea. Tel: 82-2-2290-8680, Fax: 82-2-2299-8692, E-mail: kimks@hanyang.ac.kr

(c) This is an open-access article distributed under the terms of the Creative Commons Attribution Non-Commercial License (http:// creativecommons.org/licenses/by-nc/3.0/), which permits unrestricted non-commercial use, distribution, and reproduction in any medium, provided the original work is properly cited. 
intubation with little to no sedation. There are risks associated with removing damaged granuloma and difficulty associated with advancing the tracheal tube over the fiberscope and into the trachea. We also considered using a Pentax-AWS ${ }^{\circledR}[3]$ for an awake-tracheal intubation, but with that, an assistant would not have been able to simultaneously shift the granuloma to the right. We could not promptly prepare a Glidescope ${ }^{\circledR}$ laryngoscope [4]. We have to report our recent experience of a conventional Macintosh blade for endotracheal intubation in patients with large obstructing vocal process granuloma.

\section{References}

1. Luzar B, Gale N, Klopcic U, Fischinger J. Laryngeal granuloma: characteristics of the covering epithelium. J Laryngol Otol 2000; 114: 264-7.

2. Pontes P, De Biase N, Kyrillos L, Pontes A. Importance of glottic configuration in the development of posterior laryngeal granuloma. Ann Otol Rhinol Laryngol 2001; 110: 765-9.

3. Suzuki A, Kunisawa T, Takahata O, Iwasaki H, Nozaki K, Henderson JJ. Pentax-AWS (Airway Scope) for awake tracheal intubation. J Clin Anesth 2007; 19: 642-3.

4. Choi GS, Park SI, Lee EH, Yoon SH. Awake Glidescope ${ }^{\circledR}$ intubation in a patient with a huge and fixed supraglottic mass -A case report-. Korean J Anesthesiol 2010; 59(Suppl): S26-S9. 